\title{
Aligning Efficacy Beliefs and Competence: A Framework for Developing Technical Knowledge
}

\author{
Nancy A. Inskeep and Bettie C. Hall \\ HI Consulting, Cincinnati, Ohio, USA
}

\author{
inskeepn@hotmail.com; Bettie.Hall@uc.edu
}

\begin{abstract}
Common technical problems can overwhelm managers who lack basic technical experience. Many managers eschew technology projects due to their self-efficacy, or intrinsic beliefs about their ability to successfully solve specific tasks. Competitive organizations require managers who can not only take charge of problem situations involving technology without wasting limited resources, but also leverage those resources in a manner that enhances organizational learning and reinforces knowledge management. The authors present an iterative model as a starting point for analyzing such problems. The model recognizes business competencies as a foundation for acquiring technical knowledge by examining situations through the four, iterative lenses of Objectives, Technology, Implementation, and Support (OTIS), thereby increasing the managers' organizational value, marketability, and career opportunities.
\end{abstract}

Keywords: Efficacy beliefs; self-efficacy; business competencies; skills; career; technology; know ledge management; organizational learning; technical knowledge; individual learning; OTIS

\section{Introduction}

Managers operating within today's organizations are under the constant pressure of change that results in continuous career challenges. Some of these challenges may be familiar and managers can call upon the ir past experiences to question, analyze, and address the situation. These challenges will be accepted as opportunities if the situation can be overcome by the managers' robust belief in their ability to acquire and to apply know ledge (Davenport, 2005), to use that knowledge to transform the challenge into innovation and value for themselves and their organizations (Miller, Fern, \& Cardinal, 2007), and to add the educational experiences into the ir concepts of competence (Hogan \& Warrenfeltz, 2003).

Other challenges, however, may be first encounters of the unfamiliar and unwanted kind, often involving specif ic areas of expertise or tasks that a given manager has affirmatively avoided throughout his or her career. Such challenges may be more comprehensive in nature than previously encountered and emanate from global competition or from limited natural, capital, or hu-

Material published as part of this publication, either on-line or in print, is copy righted by the Informing Science Institute. Permission to make digital or paper copy of part or all of these works for personal or classroom use is granted without fee provided that the copies are not made or distributed for profit or commercial advantage AND that copies 1) bear this notice in full and 2) give the full citation on the first page. It is permissible to abstract these works so long as credit is given. To copy in all other cases or to republish or to post on a server or to redistribute to lists requires specific permission and payment of a fee. Contact Publisher@InformingScience.org to request redistribution permission. man resources (Ireland \& Hitt, 2005). These challenges are often founded on continuous changes within the world's economies and technologies, and individual managers can feel caught up in forces over which they have no control or influence. While it is true that these individuals may have little practical impact on the underlying economic issues, it is very possible for them to be called upon to address the technical elements 
of such issues, especially if the individual possesses subject matter expertise or specific knowledge about the challenge at hand. Therefore, the question is, where does a manager begin to develop and establish the kind of technical competencies that would aid in addressing the underlying issues of unfamiliar or potentially overwhelming challenges?

The answer does not always lie in possessing, developing, or acquiring specific technical expertise in response to changes or challenges, but rather in possessing or developing basic technical competencies to begin breaking down the situation into events, units, or "chunks of information" which can be referenced, analogized, or investigated towards a resolution. In this paper, the authors present a simple technology competency model, called "OTIS," that sets forth questions to ask and areas to assess when faced with new or recurring technical challenges. The name "OTIS" is an acronym because the model presents an iterative process for assessing the Objectives, Technology, Implementation, and Support of the challenge to be addressed, as illustrated in Figure 1.

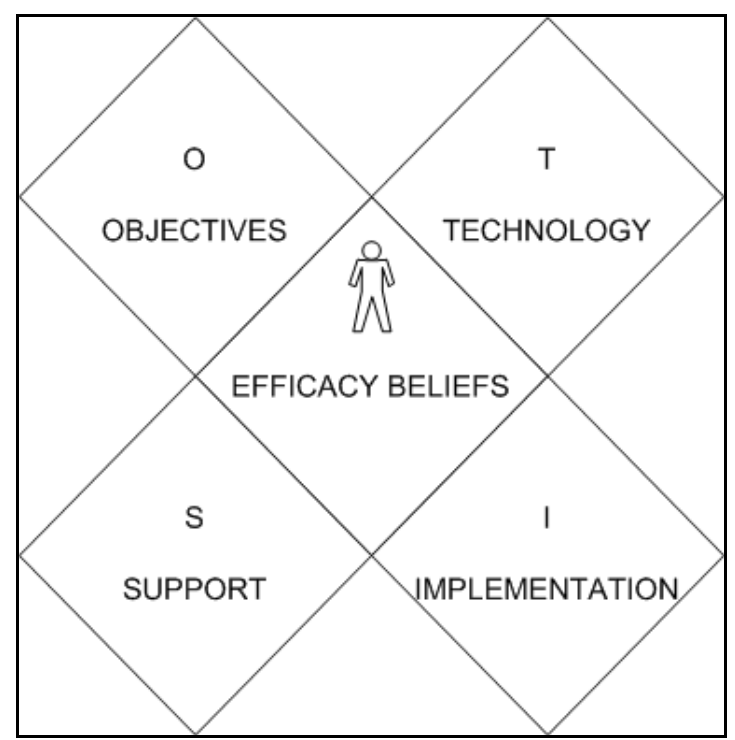

Figure 1: The OTIS competency model.

Developing a basic familiarity and eventual understanding of these key technical concepts can expand core competencies, as well as enhance career opportunities and establish credibility among peers (Hogan \& Warrenfeltz, 2003). The OTIS technical competency model can solidify managers' confidence in the ir ability to analyze and discuss technical issues within the framework of their professional expertise. For example, a human resources manager should be able to assess the functionality of a human resources information system (HRIS), while a purchasing manager should be able to define workflows and reporting needs for a requisitioning and procurement application.

\section{Approach}

The OTIS model is a starting point to help non-technical managers assess situations involving technology by understanding and relating four basic business concepts to the problems under review. The OTIS model is not intended to replace more sophisticated processes of technical analysis or management controls, such as project management or quality assurance methodologies. Instead, once managers become proficient with the OTIS model, they can extend their education and enhance their competencies by seeking out more sophisticated and comprehensive management methodologies. How can a manager's professional expertise, known capabilities, and nontechnical subject matter knowledge aid in learning technical concepts and establishing technical competencies of their own? The answer lies in the linkage of efficacy beliefs and experiential 
competencies, and how these two work together to provide the foundation for behaviors, skills, and actions.

\section{Efficacy Beliefs and Competence}

The concept of competence was originally developed by McClelland and referenced performance capabilities that differentiated effective from ineffective managers operating within a specific environment yie lding empirical results (McClelland, 1973). Since then, the idea of competencies has generally and rather simply devolved into a list of desirable skills and traits along a business construct, usually grounded on management, expert, or professional criteria and assessed by observable performance or interviews (Boyatzis, 1982; Hogan \& Warrenfeltz, 2003; McClelland, 1998; Spencer, \& Spencer, 1993). Business competency models are usually organized along four general competency domains involving intrapersonal skills, interpersonal skills, leadership skills, and business skills (Hogan \& Warrenfeltz, 2003; Warrenfeltz, 1995).

The components of these skill domains are transferable across industries, services, and professions. For example, basic business skills such as time management, strategic planning, and financial know ledge are valued by and transferable among private, public, and political entities on a global basis. A simple Internet search yielded a "Strategic Military Leadership Model" with the desired competencies and skills of self-development, thinking skills, communication skills, leading organizations, leading people, and leading transformation (http://leadership.au.af.mil/slsskil.htm ).

The problem with some managers is that while they may possess the competencies necessary to tackle technical problems, they often lack the confidence that the skills they possess and the know ledge they have acquired is sufficient to address the task at hand. Under these circumstances, the individual manager's self-efficacy beliefs are impacting his or her ability to act and manage the situation.

The concept of self-efficacy refers to beliefs about oneself, and specifically, the belief people have about their ability to produce desired results through the ir own efforts (Bandura, 1977). These self-beliefs provide the ability to control individual thoughts, feelings, and actions. Selfbeliefs are not directly measurable, so one cannot "know" how confident a given manager may be in his or her competence. One can only observe the external manifestations of internal beliefs, which is to say, their verbal and nonverbal communication and behaviors. Still, it is important to try to measure beliefs, since what people believe about their ability to perform a given task can be a very strong predictor of their future performance of that task. This concept has been oversimplified as "self-fulfilling prophecy," but it extends beyond just making personal predictions (Bandura, 1986). It has been proposed that one of the effects of self-efficacy beliefs is that it determines how much effort people will put forth to accomplish something, how long they will persist when confronting a barrier, and how much resilience they will demonstrate in the face of inevitable adversities (Bandura, 1997). People with high self-efficacy may be more persistent in finding ways to incorporate changes in ways that are beneficial.

Of course, many factors come into play when facing a new or complex technical problem or issue. Experience with the technology, experience watching someone else solve technical problems, verbal encouragement or confidence expressed by one's supervisor, and one's own optimism or mental state, all play a role. Other influences include the difficulty of the problem to be solved, whether the issue is one that has been solved by others, whether it has resulted from some new interaction of technology, one's prior success or failure involving technology, and previous feedback (Marakas, Yi, \& Johnson, 1998). There are also personal factors that can alter efficacy beliefs and estimates, such as the amount of effort or resources available to resolve the problem or the impact of one's mental and physical health. 


\section{Impact of management experience}

Factors that exemplary managers perceive as helpful in overcoming barriers may prove to be intrinsic ones, such as beliefs, attitudes, and confidence. Self-efficacy is a dynamic construct that changes in strength and intensity as a person tackles new problems, learns new skills, and develops or inhibits abilities. The avenues of self-efficacy development and growth are available to managers. How one explains past failures is an important aspect of efficacy. In people with high self-efficacy, failure is most often attributed to lack of effort. Numerous problems may be blamed, however, for people having low self-efficacy. Other people can also affect a person's self-efficacy by offering him or her experiences that will build confidence and abilities that strengthen self-efficacy, or by offering experiences that diminish confidence and decrease selfefficacy. Finally, people can learn to interpret their own physical and emotional arousal states, and can learn the role these play in the ir success or failure when performing tasks or achieving goals (Bandura, 1995; Marakas et al, 1998). Individuals can learn and practice methods of selfregulation to minimize the impact of tension, nervousness, or other anxieties that potentially impact their efficacy beliefs and their resulting performance.

\section{Impact of efficacy beliefs}

Self-efficacy beliefs can impact performance and results in many ways. These beliefs can be cognitive in that people may be optimistic or pessimistic when thinking about a problem or their future performance of a task. Self-efficacy beliefs can motivate people to accept challenges or to decline them. They can have emotional results, particularly in how people deal with depression and the stresses associated with their own or vicarious experiences. Finally, self-efficacy beliefs can affect the decisions people make, such as whether to attempt a goal or task. Self-efficacy beliefs are asserted to be more predictive of future attainment than people's current knowledge, skills, or previous accomplishments (Zimmerman, 2000). This has important implications for any study of or opportunity for human development, particularly when faced with a new challenge or complex endeavor.

Visibly recognized skills may represent or reflect competence, but they do not always equate to competence. It is possible to have a solid skill level but still lack an effective and desirable level of competence. It is possible to have confidence but little competence. It is possible to do something right, yet have it turn out to not be the right thing to do - to perfectly do the wrong thing. Situations involving technical solutions are often high-risk efforts and critical to organizational success. Organizations do not expect their managers to become technical experts, but they can and do expect their managers to understand and appreciate technical concepts, just as managers are expected to understand basic financial and human resource theories. Managers can use their business skills, core competencies, personal confidence, and efficacy beliefs about their abilities to enable the acquisition of technical know ledge and expertise, as well as enhance their value to and effectiveness within the organization.

\section{OTIS: A Technical Competency Model}

Technical skills are just as valued and transferable as business skills, but they usually take years of direct experience and extensive education to acquire. However, technical competence and its associated knowledge can be developed at any stage in a career and will provide managers with the basic skills to assess situations, analyze information, and define solutions. The development of technical assessments and solutions to address everyday business needs is consistent across subject matter and content areas, such as the need to keep information current, to ensure information is assessable and extractable, and to ensure a technical solution is logical and intuitive. In essence, one of technology's underlying purposes is to distribute knowledge and information in a current, accessible, and useful manner (Davenport, 2005). 
As with any challenge or problem, the starting point is to ask questions, elic it information, build a framework of references that align with one's knowledge and experience, seek the assistance of others when one's own references are insuffic ient, use the inferences and advice to define the situation into manageable issues, and then begin resolving those issues. The OTIS model supplies the framework for building technical knowledge and establishing technical competence upon the foundation of the manager's efficacy beliefs. These beliefs are inferred from, and are a reflection of, the ir basic business skills, competencies, and personal confidence. The iterative framework of OTIS is illustrated in Figure 2. Each component will now be examined in further detail.

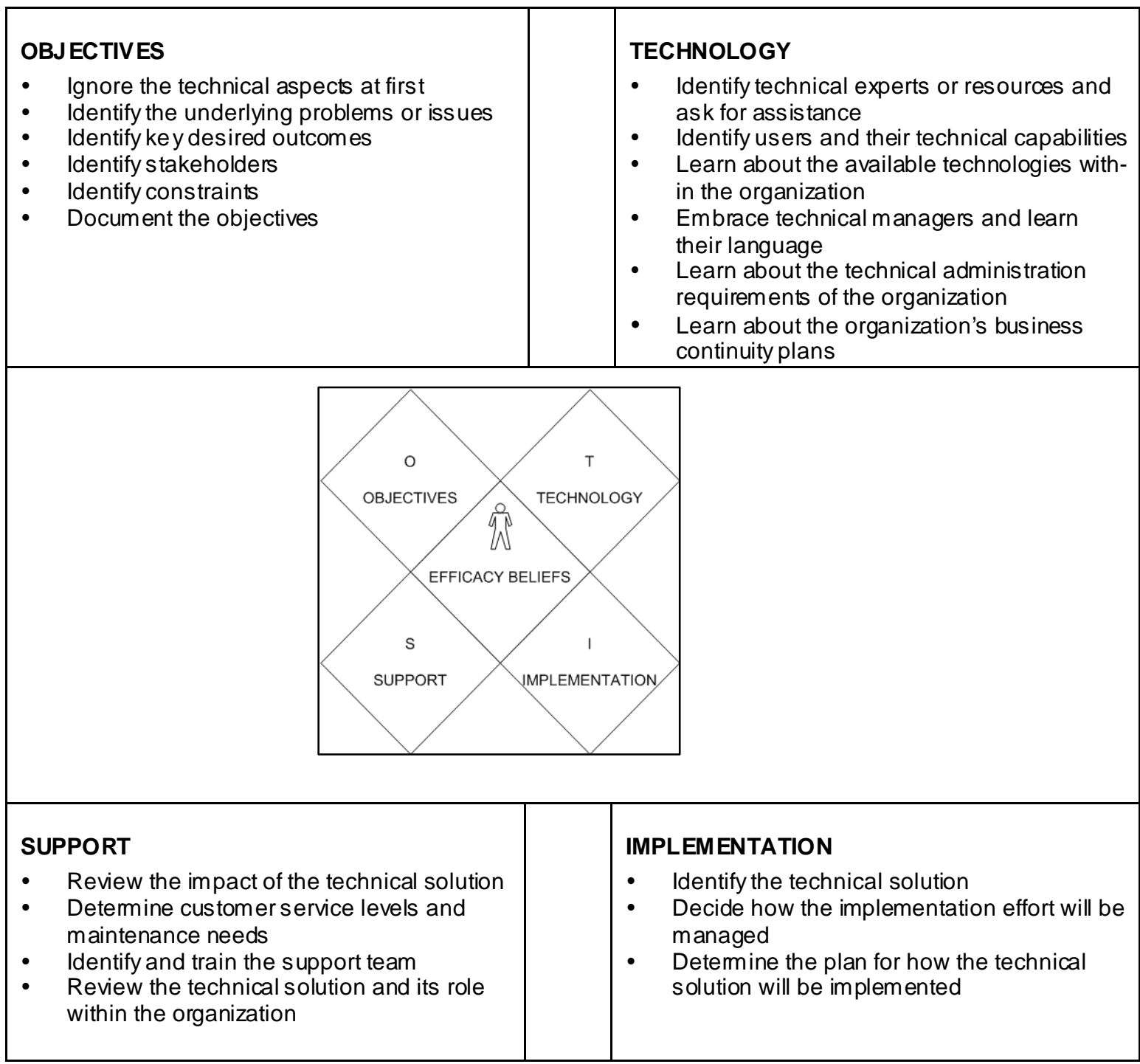

Figure 2. The OTIS technical competency model--an iterative frame work

\section{Objectives}

The first question to ask oneself when faced with technical issues or problems is, "What are we trying to accomplish?" To successfully identify the objectives of what needs to be accomplished, managers should assess the situation as many interacting layers and along several criteria. Managers need to gather facts and expert opinions to adequately identify any problem and its cause, as well as to ensure that they are addressing the correct issues that resolve or mitigate the situation. It may be beyond the organization's managers' abilities or given resources to identify the core 
problem and its underlying issues, develop a solution, and resolve that problem in its entirety, but it is reasonable to expect them to provide some relief, establish some control, and move the organization in the direction of a desired solution. Identifying the problems and the ir underlying issues, the desired outcomes, the stakeholders, and the associated constraints are logical, interrelated methods for assessing situations. This analys is will establish a solid foundation by clarifying objectives and determining how to accomplish them.

Ignore the technical aspects at first. When called upon to assess any business situation, whether it involves technology or not, one starting point is to learn about what is going on in terms of operations, functions, users, clients, etc. Overall, the task is to examine, learn, and eventually understand the relationships among the problems and issues. One cannot assume that the mere presence of technology will require a technical solution. However, it is unlikely that any comprehens ive solution to an operational or functional issue involving technology will not involve a technical element within the solution. Regardless, ignore the specific technology when completing an initial assessment of most situations in order to concentrate on the problems, not the solutions. This strategy can be followed even if the problem is known or perceived to be a technical problem. Focus on the problems and issues, rely on management experience and skills, and investigate the situation to determine what needs to be accomplished to alleviate that situation.

Identify the underlying problems or issues. One should always try to begin at the beginning and identify the current state. What started this situation? Is it in its infancy or original form, or has the situation evolved and escalated to such a state that no one clearly knows how it began or what is actually happening? Too often, managers are directed to "fix it" without a clear understanding of what "it" is. People will have a different opinion of what is going on and what is needed. It is not enough to know that sales are down, costs are up, or an audit found an accounting error. More specific and accurate information is needed.

The goal is to identify the current state as accurately as possible to ensure the correct problems or issues are being addressed. Under the best circumstances, a needs assessment should be completed that identifies the current state, the desired state, and the gaps between those states. The primary benefit of a needs assessment is the development of the "big picture," which lays the foundation for a comprehensive understanding of the various relationships and eventually supports a coordinated set of solutions. However, proper needs assessments take time, personnel, and funding to complete. It is not uncommon for the organization to be under pressure to find a solution, and there is no time or resources to perform a detailed needs assessment. Under these circumstances, managers need to do the best they can do with the allotted resources. If the people who need to be involved know each other and function well together, the most efficient method is to hold a meeting and have everyone declare what they know, what they think, and what they need. The core problems are usually at the intersection or common points of this information. If the people do not know each other well or do not work well together, then more preparation is needed. Contact the key personnel who have the most expertise, are the most respected, or have complained the loudest. Use their information to build an agenda, or "straw man," and have that as the starting point for the meeting's discussion; be as non-confrontational as possible to elicit what the group knows, thinks, and needs. Again, the commonality of information will usually yield at least part of the underlying problems or issues.

Identify key desired outcomes. Once the current state is identified, the desired state needs to be defined. What outcomes are expected? What should the future look like? For example, sales should increase, costs should decrease, and the accounting error should be eliminated. However, more detail is required, such as the specific goals needed to achieve the desired outcomes. Concentrate on defining what is wanted in terms of operations, functionality, and support. Create statements describing this desired state, which essentially establishes a basis for the business requirements. If specific goals are not possible to identify at this time, then directional goals may 
have to suffice. Finally, if managers do not know or cannot infer the desired outcomes based on the current information then begin developing a list of undesirable outcomes specifying what is not wanted. Eventually, patterns will emerge that will clarify the desired state or direction to pursue. Then, solutions or options should become apparent.

Identify stakeholders. Another starting point for resolving any problem or issue is to identify who is involved in the situation and what role they play in its management and support. A simple rule should be that anyone who can help resolve the situation to a satisfactory conclusion, or is directly impacted by that conclusion, should be involved in the endeavor. Entities that are directly impacted by the effort are referred to as primary stakeholders, with the common examples being executive sponsors, functional and technical subject matter experts, project managers, internal clients, suppliers, or sales distributors. They are directly involved in the problem and its eventual solution. People or organizations that are indirectly or remotely impacted by the endeavor are referred to as secondary stakeholders, with common examples being external clients, regulatory agencies, or investors. Secondary stakeholders may have some level of interest in the situation or may even provide guidelines that impact the resolution, but they usually do not directly assist in developing and implementing the resolution itself (PMI®, 2000, 2004). The goal is to not only identify and recruit the primary stakeholders that can directly aid the endeavor, but to also monitor and consider the interests of the secondary stakeholders that may influence or be influenced by the effort.

The key to dealing with multiple stakeholders is keeping an open mind and listening respectfully to their concerns and feedback, realizing that everyone has different foundations of expertise, experience, and know ledge. A stakeholder may not be eloquently or accurately expressing his or her concern, but that does not make the comment irre levant or invalid.

A solid method of dealing with comments or feedback is to question the concerns, document them as risks, and establish better controls to ensure the delivery of what needs to be accomplished. Once documented, assign the control or mitigation of the risks to the appropriate parties, which is often the person who raised the issue. Involve the parties who are concerned about the process and solution in the execution of those processes and solutions. The overall endeavor may involve technology, but the underlying problems and risks are basic business issues that both nontechnical and technical managers skillfully address everyday.

Identify constraints. It is extremely rare to approach a problem or issue with an "open checkbook" having unlimited resources to investigate and assess the situation and develop a precise solution. For this reason, identifying constraints may also be a good starting point of the analys is. For example, if the deadline for a solution is due within a few days, the manager knows that he or she has very limited options, such as little time, reliance on experienced resources, requiring a highly manual solution unless automated solutions can be manipulated or reprogrammed within the tight timeframe. During the investigatory activities, it is very likely to encounter many limitations or barriers that must be evaluated and balanced against each other prior to framing the assessment and any workable solutions. The volume, size, and inflexibility of these constraints will limit the managers' options for developing comprehensive and quality alternatives.

A common reference for these limitations is the "triple constraint" of scope, resources, and time (DeCarlo, 2004; PMI®, 2000, 2004), as well as quality and customer satisfaction, which result from manipulating th triple constraints (Brooks, 1995; PMI®, 2004).

Document the objectives. Objectives describing what needs to be accomplished should be documented in an executive summary, a business plan, a problem statement, or even a simple email that captures the problems and issues, key findings, possible solutions or options, and action steps. These objectives describe the resolution of the gaps between the current and desired states; the specific measures needed to close the gaps are essentially the requirements. Formal documen- 
tation of the situational analys is establishes that the problems or issues were recognized, investigated, and assessed at some level to identify alternative actions or resolutions. It provides a baseline for the endeavor, as well as a central point of understanding. Documentation creates an audit trail establishing that some level of due diligence was performed by the management team. Also, the stakeholders are presented with one more opportunity to refine or object to the statements declaring what needs to be accomplished and the potential actions for accomplishing those objectives.

\section{Technology}

What technologies are needed to accomplish the objectives? What resources are available to use in terms of experts, equipment, or funding? Where do managers begin when they do not even know what to ask? Under such circumstances, managers begin by telling, listening, and eventually learning.

Identify technical experts or resources and ask for assistance. As a manager faced with a technical challenge, the situation often seems intimidating and overwhelming. Manage it as any other problem or issue: seek expert or experienced assistance, explain the situation, and take what advice or information is offered to furthering one's knowledge and resolving the problem. The best scenario is that a technical support team is already in place and acting as the technical resources. If this is not the case, or if a second or more objective opinion is needed, there are methods for seeking out technical expertise and assistance. First, the manager should ask his or her supervisor if there is a designated technical manager or contact for the department. Sometimes an organization will assign an engagement manager or a project manager as a technical resource to the division or department. If not, ask the supervisor if he or she has an informal technical resource to approach for advice. Finally, the manager should let the supervis or know that he or she will inquire about alternate internal assistance by using the organization's email or telephone directories to contact technology managers. The manager can begin by checking listings for "information technology," "information systems," "engagement management," and "project management office" or "PMO." Once contacted, politely ask the managers for a moment of their time, and explain the situation in terms of the current state, the desired state, and the identified gaps. One does not need to identify the technology to use or the solution itself. The technical resources within the organization will provide this guidance based on their resources and standards.

What if technical resources do not exist within the organization? Where does one begin if everything is outsourced? What if the organization is small with a single person acting as the technical department? The actions to take are the same regardless of size and technical support; seek out experts and ask for guidance. With an outsourced environment, contact the outsource company's relationship or sales manager, explain the situation, ask for help, and follow-up on the ir advice. Suppliers' relationship or sales managers are in the business of establishing and ensuring a continued relationship with the client organization; they can be valuable resources to learn about current technologies and options.

In the case of a small organization with little or no internal technical expertise, contact and chat with external experts, such as consulting companies, friends or acquaintances in technical fields, or local business or technical universities. Consulting companies want to acquire clients and establish relationships. They are generally willing to discuss the situation, communicating whether they would be interested in such a project, or if not, who of their peers or competitors might be interested. Friends and universities can also provide solid direction and advice, even if they are unable to directly work on the projects themselves. Use their advice to construct Internet searches to find white papers, open houses, and other educational opportunities and contacts. Also, a small business's own professional support faces similar challenges acquiring technical support and expertise; for example, what technical services does the business's external accountant or legal 
counsel use? Finally, contact professional organizations like local chambers of commerce, technical "incubators" or business communities, retired executive associations such as SCORE® (Service Corp of Retired Executives), or professional associations such as local chapters of the Project Management Institute (PMI®).

By accessing these contacts and learning from the ir expertise, managers cannot only improve their own technical know ledge and ability to discuss technical subjects, but they can also gather the necessary support and documentation to take back to their management or owners as proof that the endeavor itself cannot proceed based on the current available resources or under the current circumstances. This is a classic "make or buy" scenario. If the resources do not internally exist to develop and implement the identified solution, the only options are to restructure current resources, acquire external resources, downsize or de-scope the solution, or leave the situation as is by abandoning the effort altogether.

Identify the users and their technical capabilities. It is always wise to know one's audience. The users or clients involved in the problem or issue being assessed need to be identified and evaluated in terms of their technical capabilities. Are they computer literate? If so, are they experienced with common desktop software applications? Or, do they just use menu-driven proprietary applications supporting limited and specific organizational functions, such as manufacturing or time reporting applications? Managers need to determine the users' level of expertise and sophistication, as well as ascertaining the users' prospective level of support for the project or endeavor. Will the users help or hinder the prospective solutions to the problem or issue? What are their capabilities, and what are the potential training needs?

Gaining user support is critical to the success of any effort, not just in the selection and implementation of the solutions, but also in the acceptance and efficient use of the technologies, processes, and practices affecting their jobs and the performance of those jobs. Managers should identify users who can be change agents. However, managers should not limit the search to only the "best" people. Often, the critical or cynical users that understand the pain points and inefficiencies of the current situation are the best change agents because they are ready to embrace a better environment; they have been waiting for change (Selander \& Kalling, 2007).

Learn about the available technologies within the organization. One does not have to become a technical expert to understand and appreciate technical concepts and the people who support the organization's technical functions. In its simplest form, technology falls w ithin three categories: hardware, software, and infrastructure. Hardware refers to physical equipment, such as desktop computers, laptop computers, servers, routers, and data storage devices. These items are easily touchable, generally movable, and require specific, protective environments or handling to remain functional. For example, servers and storage hardware require a temperature-controlled, electronically sound environment to function properly, us ually within a protected data center. A laptop requires a padded case to protect it from breakage or damage. Software is best described as the brains that drives or makes the hardware function. Examples of software include programs, routines, formulas, and algorithms that direct the operation of the hardware. Infrastructure is the underlying connectivity, network, or environment that enables hardware and software to work together and communicate with each other, within the organization, and with the external world. Think of infrastructure as the roadways and utilities required for the organization's technology to work.

All technical solutions require these three elements of hardware, software, and infrastructure. For example, a small business may only need a desktop computer and an accounting software application to support its invoicing and receipting functions; the only infrastructure needed is electricity and a generally dry environment. In contrast, a large organization with an international client base needs comprehensive systems to support its invoic ing and receipting operations, maybe sev- 
eral to support financial and cultural initiatives. In general, the term "application" refers to a software package and its functions, while the term "system" refers to the overall technical solution and its interacting hardware, software, and infrastructure. Managers do not need to be experts regarding the technical elements; they only have to realize what element is being discussed and to understand how that element fits within the solution.

Embrace the technical managers and learn their language. Most technical support staffs are centralized or "pocketed" throughout an organization. The same technical personnel will probably be continuously encountered, for most projects and for most problems, throughout the manager's career within the organization and also within the industry. It serves no purpose to be confrontational or disrespectful to one's technical peers. The world grows smaller everyday, and it is surprising how often people within the same industries or services, especially technical fields, will not only encounter each other again but will often be involved in similar job changes and hiring processes. Non-technical managers need to establish cordial and respectful relationships with their technical brethren; their counsel and support will be invaluable to the managers' career success in their current and future positions. The formal and informal associations that develop between managers and their technical contacts can form strong networking and mentoring relationships that can last for decades. Non-technical managers will quickly discover that technical managers often need and want to understand who is at the other end of the technology that they support. Most technical managers are just as interested in supporting the ir clients, ensuring qua lity, and delivering stable services as non-technical managers. Non-technical managers should inquire about the technical managers' organizational structures, their preferred types of technologies and manufacturers, and their current vendor partnership agreements.

Most organizations control expenses and support processes by using only specific technologies and manufacturers. There are too many technical alternatives for a single organization to effectively and economically support. For example, it is unrealistic to expect the same technical manager to have the expertise and skills to successfully maintain desktop support, enterprise storage, and mainframe operations. While a technical manager can appreciate these different technologies and understand their basic operational needs, these are very different elements requiring unique skills sets. The same issues arise when supporting different vendor technologies.

One method for processing and organizing this information is to develop a "cheat sheet" of the organization's current technologies and their manufacturers. It is also beneficial to note the technologies and manufacturers that are not being used. This information can come from the technical managers and also from the purchasing or procurement managers. It is enough to know that "we are an 'XYZ-shop", or "we are not an 'XYZ-shop," meaning the organization does or does not use XYZ technologies or products. Then as the managers participate in discussions about possible technical solutions or attend vendor presentations, they can take notes, capture terms, look for exceptions, and spot the issues. Finally, consider the issues against the constraints of scope, time, quality, customer satisfaction, and the resources of money, equipment, and people. The organization is currently not an XYZ-shop and never has been. What is the financial and human impact of selecting an XYZ solution? The XYZ solution is state-of-the-art and the clients really want it, but what will happen to the scope and timeline of the project if the organization selects XYZ? Within this framework, managers can assess the technical issues by relating them to and relying on their business competencies and expertise. It is reasonable for the organization to expect its nontechnical manager to identify these types of issues and communicate their impact or concerns to executive management.

Learn about the technical administration requirements of the organization. In addition to understanding the technical elements of hardware, software, and infrastructure, it is also necessary to understand the administrative requirements of establishing and supporting a quality, serviceoriented technical operation. The technical operations of an organization and the controls needed 
to properly manage them represent an extremely expensive and critical responsibility having inherently high risks and liability issues. Technical administration is not an area to be disregarded. The core of an organization's technical operation will be its data center and associated infrastructure, such as telecommunications, electric or power supply, air and heat controls, and water supply. The data center will be managed according to strict environmental standards and protocols to ensure a stable and efficient technical operation. In addition to environmental controls, there will be physical and technical security polic ies and procedures. Physical security will take the form of a protected facility, often remotely located. The location may be physically secured with fences, registration facilities, guards, locked entries with coded or biometric access control, and camera recording and monitoring devices. The technical elements themselves may be protected against unauthorized use or entry, such as firewall programs and audit logs. Specific applications will have entitlement controls requiring user identification and password codes.

In addition to upfront protections against unauthorized access or users, data residing in databases and storage mechanisms are secured with encryption techniques and additional access controls. Data represents the organization's knowledge and assets. It may be proprietary in nature such as product schematics or manufacturing processes. Data may involve personal or non-public information, such as customer sales transactions that include payment details or employee benefit records. Data that is designated as personal and private, such as personal identification numbers, requires strict handling, storage, and destruction procedures.

Learn about the organization's business continuity plans. Technical solutions and their support often operate "24/7," or "twenty-four hours a day, seven days a week." The need for and reliance on technology is so pervasive, everyone expects it to be constantly accessible and responsive. Outages or delays are not an option in today's competitive, global environment. A back-up plan is needed for all of the organization's technical elements and for their associated administration or management. All organizations regardless of size need business continuity plans that describe how the organization will respond to unannounced events and how it will continue to operate under short-to-mid-term timeframes and conditions.

Related to business continuity plans are disaster recovery plans, which are detailed documents that describe how the organization's technical assets and resources will return to production. Most mid-to-large organizations will have back-up sites for their data centers, or disaster recovery sites, that mirror the original data center operations and their data. Even small bus inesses should be backing up their data to external storage devices. Managers need to appreciate the complexity and juxtaposition of the technical operations during times of crisis. Software applications cannot come back online simultaneously due to power and resource constraints. Therefore, applications are prioritized based on criticality and need, and they are turned on according to infrastructure availability and agreed upon service agreements. It is realistic to define a solution in terms of normal operations, business continuity and disaster recovery conditions, and "what do we do in the meantime" responses, such as relying on manual processes or support.

\section{Implementation}

Another step in assessing technical problems and their solutions is to define the implementation effort. How will this project or process be accomplished? Actual implementation efforts can be extremely detailed and vary depending upon the complexity of the solution. However, there are basic tasks and elements common to implementation efforts.

Identify the technical solution. Once the problems and objectives are identified and the available technologies and solutions are reviewed, a recommendation needs to be developed and decisions need to be made; even if the recommendation is to do nothing, that action needs to be documented and presented to management. In an organizational setting, the decision making process 
will be a team effort, with executive management determining which of the team's recommendations, or some version thereof, to allocate resources and implement.

Developing a final recommendation or prioritization of options is a team effort requiring strategic and negotiation skills. Often, the line of business will select the best functional solution, or rank two or three alternatives. The technical experts will identify the technical elements required to implement each solution. Other team members also evaluate each alternative, such as the finance manager completing financial analyses and the risk manager providing risk assessment reports. In essence, the team develops a recommendation for its executives by identifying the desired solution and preferences, determining technical and implementation needs, and balancing these against the constraints of what is reasonable and what is best for the organization.

The list of items to review and questions to answer when selecting the solution can be extensive, especially if the solution is complex and expensive. The basic question regardless of the situation is often, "Do we "make it' or 'buy it' to accomplish the solution?" What organizational resources are needed to support a small or large project, or a short-term or long-term project? Is this a "must do" or "should do" project, and what level of scrutiny will the effort encounter? Finally, does the organization have the core competencies, as well as the basic resources, to successfully accomplish the project or solution? Once the implementation concerns are evaluated along a "make or buy" continuum, the practicality and viability of each solution becomes apparent and consensus for the recommendation is usually formed.

Decide how the implementation effort will be managed. Before the technical solution is implemented, managers need to determine how to manage the implementation process. This is another opportunity to identify any missing tasks or elements prior to expending funds, committing resources, and communicating decisions. How will the implementation be managed? What level of control or rigor is required? Who will actually be responsible for what tasks?

As with the decision process, it is useful to determine the solution's management based on the "make or buy" elements. If the solution is essentially an internal organizational effort, then processes and controls may exist to manage the implementation, such as following internal project management, accounting, and information technology processes and procedures. When the solution is "bought" or externally sourced, the vendor or supplier should have specific implementation plans and procedures detailing how it "on-boards" or "turns up" clients. Managers should ask the supplier for samples of implementation plans, contact information for recently onboarded clients, and meetings with implementation and operational support representatives to verify that the supplier can deliver on its assertions and commitments. When the solution is externally sourced, the organization will still manage the internal effort, but its supplier should define and drive the overall effort; the organization is relying on the supplier's expertise and laying the foundation for a successful partnership. If the supplier does not step up and meet the organization's expectations and requirements, then the managers should immediately begin managing the gaps or areas that the supplier is not supporting. It is not unusual to stop the project, assess the supplier's performance by comparing what was expected versus what was delivered, review the impact of the supplier's actual performance on the organization's resources and operations, and determine if the effort should continue with that supplier.

Determine the plan for how the technical solution will be implemented. Managers need to develop a roadmap for how the solution will be implemented. What tasks need to be accomplished, and what is the scale of the effort? How are the pieces of the implementation going to fit together in terms sequencing the events? Do hardware, software, and infrastructure need to be acquired? If so, how should their de livery and installation be scheduled to ensure that the predecessor activities, like hardware installations, are completed prior to successor activities, like software installations? Various documents will support this process, such as a project plan, a detailed work break- 
down structure, various conversion plans, and a purchase acquisition plan. If the solution is externally sourced, the supplier should have detailed plans and documents describing what needs to be done. If the solution is internally sourced, then the management team needs to determine these tasks.

At its most basic level, the management team must bring together the human and non-human elements, as well as the physical and non-physical requirements, to successfully complete the implementation. The physical elements are easier to identify: equipment needs to be ordered, offices need to be established, users need to be identified and trained. The non-physical elements are more elusive to identify: define the data to migrate, identify applications that need to interface or "talk to each other," or develop a test plan that ensures the new system and processes effectively replace the current system and processes. Managers do not need to know the specific details and timings, but they do need to appreciate the detail required and effort involved to complete all of the tasks in an organized and sequential manner. It is a time-consuming effort to develop task lists and other project documentation and that effort needs to be recognized as one part of the workload when planning the implementation.

\section{Support}

A final area to consider is support. Once the solution is in place, how should it be supported? What will the organization do with it? Is the solution an asset that can be leveraged within the organization? Should the solution be actively managed to ensure its continued functionality and growth, or is the solution completed, as is, with no further effort needed? The former will require resources to support and maintain the solution, while the latter will meld into the working elements of the organization and will generally be forgotten. Therefore, managers need to determine the solution's actual or potential impact once it is implemented and in production, and what role, if any, that solution has in the overall organization.

Review the impact of the technical solution. Once in production, managers should revis it the solution, its users or clients, and its impact on the original situation or problem. Has the solution been effective? What do the users or clients think? Did the solution help or hinder? If it helped, is there a desire to grow or expand the solution? One starting point is to review the users' original requirements and expectations, and assess them against the actual results from or performance of the solution. Discrepancies may be due to the non-delivery of the requirements, where these needs are now being met by alternate methods, or the requirements were de-scoped as not being necessary or due to resource constraints. Managers should review the solution's effectiveness and identify what it needs to remain operational. Specifically, it is not uncommon to learn about downstream errors or horizontally related operational problems; in such cases, a stakeholder may have been overlooked, or horizontal or downstream processes may have changed during the time of the project's implementation. Next, managers should ascertain the users' current needs regarding the solution. The users may have identified modifications or enhancements to the solution. Also, the role of the users should be evaluated to assess the solution's impact on their job functions, performance, and productivity. For example, job task evaluations and training assessments are common to determine the impact of technology on the department and organization. Finally, inefficiencies should be identified and addressed, such as turning off unnecessary or modifying current features within a software application.

Determine customer service levels and maintenance needs. Regardless of the solution be ing internally or externally supported, a service level agreement (SLA) should be established to document the expected performance expectations of the solution. The users' operational requirements should provide a foundation for the SLA's standards. Common SLA requirements inc lude a solution's operational or "up" time, technical support's response time, escalation procedures and timeframes, delivery times and dates, the format and media of the deliverables, and activities or 
tasks that are normal and expected, versus activities or events that are outside of the scope of the SLA or support agreements. Essentially, the more critical the function or solution, the more extensive the service level expectations and maintenance needs; as well as then greater the amount of human and monetary resources required to support them.

Identify and train the support team. If the solution requires continued support and maintenance, then a support team needs to be established. The support team's members will need technical and management skills, as well as some level of operational know ledge to appreciate the solution's functionality and understand how the users actually utilize the solution. Therefore, initial and continued training of the support team is vital to the solution's efficient and effective operation.

The support team may be internally or externally sourced depending upon the solution itself. Solutions that are internal to a specific department are generally supported within that department, while broader solutions impacting the overall organization usually have a centralized support team or help desk. It is not uncommon for members of the implementation team to continue on as support personnel. The users and the support team should establish a cooperative and friendly working relationship; user groups or quality teams are forums for users and support managers to network outside of their usual roles. Often, the entire support and user structure may virtually interact, where they never meet face-to-face (Kikrman, Rosen, Tesluk, \& Gibson, 2004; Malhotra, Majchrzak, \& Rosen, 2007). In such cases, clear processes and procedures, as well as management and team empowerment, are essential for efficient operations.

Review the technical solution and its role within the organization. Technical solutions require support and maintenance. These "care and feeding" tasks need to be identified, funded, implemented, and monitored. The technical elements of hardware, software, and infrastructure will face a regular flow of potential changes. Hardware is usually tested on an annual basis and may face version or parts upgrades. Releases of new enhancements, "bug fixes," and "patches" of program code are common to software applications. Infrastructure elements, especially communication lines, are subject to service interruptions like cable cuts or changes in suppliers. New projects or systems coming into the data center may also impact the existing technical solutions, such as having the solutions share hardware like servers or storage, or having to adjust process or job control schedules to manage the increased workload within the data center. Managers cannot specifically antic ipate these changes, but such changes are not unexpected or unforeseeable. Managers need to clearly define the priority of the solution and its criticality within the overall operation of the department or organization. The higher the criticality, then the higher the risks, and the more necessary it is to provide management and resources to ensure the solution's continued operation.

\section{Conclusions}

The authors' purpose for developing and presenting the OTIS model is to enable managers to quickly assess their existing know ledge and skills, and to bring whatever resources are available to bear on the problem. Managers are required to assess and analyze situations in a way that will neither drain the organization based on overconfidence in incomplete know ledge, nor lead to paralys is resulting from incomplete know ledge or lack of experience. The OTIS model's purpose is to demystify the often intimidating and uncertain nature of problems and issues requiring technical solutions by providing a simple and logical assessment framework to scale and scope situations, to e licit and organize information, and to enable understanding and learning by referencing and relying on the manager's skills, competencies, and confidence that support efficacy beliefs. Problems requiring technical solutions can be assessed in the same manner as any other business issue.

The key to problem-solving with the OTIS model lies in its iterative nature; there is no "one time" analys is, design, and application. The questions to ask and areas to investigate can be presented in 
any technical situation, and the order of presentation may vary depending on the specific situation's facts and assumptions. The model is flexible and implies that by understanding key technical concepts and by knowing the organization's technical resources, operations, and standards, managers can bring the current environment to bear on any technical problem or issue. When the managers align the ir efficacy beliefs with the ir organizational knowledge, they become invaluable to their current organization and enhance their marketability and career opportunities to other industries and entities.

\section{References}

Bandura, A. (1977). Self-efficacy: To ward a unifying theory of behavioral change. Psychological Review, 84, 191-215.

Bandura, A. (1986). Social foundations of thought and action: A social cognitive theory. Englewood Cliffs, NJ: Prentice Hall.

Bandura, A. (1995). Exercise of personal and collective efficacy in changing societies. In A. Bandura (Ed.), Self-efficacy in changing societies, 1-45. Cambridge, UK: Cambridge University Press.

Bandura, A. (1997). Self-efficacy: The exercise of control. New York: W. H. Freeman and Company.

Boyatzis, R. (1982). The competent manager. New York: Wiley.

Brooks, F. P. (1995). The mythical man-month: Essays on software engineering (20th ed.). Boston, MA: Addison-Wesley Professional.

Davenport, R. (2005). Why does knowledge manage ment still matter? $T+D, 59(2), 18-25$.

DeCarlo, D. (2004, Ju ly). Triple constraint - Friend or foe? ESI Horizons. Retrieved December 18, 2007 from http://www.esi-intl.co m/public/publications/0704tripleconstraints.asp

Hogan, R., \& Warrenfeltz, R. (2003). Educating the modern manager. Academy of Management Learning and Education, 2(1), 74-84.

Ireland, R. D., \& Hitt, A. H. 2005. Achieving and maintain ing strategic competitiveness in the $21^{\text {st }}$ century: The role of strategic leadership. Academy of Management Executive, 19(4): 63-77

Kikrman, B., Rosen, B., Tesluk, P. E., \& Gibson, C. B. (2004). The impact of tea me mpowerment on virtual team performance: The moderating role of face-to-face interaction. Academy of Management Journal, 47(2), 175-192.

Malhotra, A., Majchrzak, A., \& Rosen, B. (2007). Leading virtual teams. The Academy of Management Perspectives, 21(1), 60-70.

Marakas, G. M., Yi, M. Y., \& Johnson, R. D. (1998). The multilevel and multifaceted character of computer self-efficacy: Toward clarification of the construct and an integrative frame work for research. Information Systems Research, 9(2), 126-163.

McClelland, D. C. (1973). Testing for competence rather than for "intelligence." American Psychologist, 28(1), 1-14.

McClelland, D. C. (1998). Identify ing competencies with behavioral-event intervie ws. Psychological Science, 9(5), 331-339.

Miller, D. J., Fern, M. J., \& Card inal, L. B. (2007). The use of knowledge for technological innovation within diversified firms. Academy of Management Journal, 50(2), 308-326.

Project Management Institute, Inc. (PMI $)$ ). (2000). A guide to the project management body of knowledge (PMBOK® guide). Newtown Square, PA: Author.

Project Management Institute, Inc. (PMI®). (2004). A guide to the project management body of knowledge (PMBOK® guide) $\left(3^{\text {rd }}\right.$ ed.). Newtown Square, PA: Author. 
Selander, L., \& Kalling, T. (2007). The surprise of candor: Employee cynicis m and technological change in late modernity work. Academy of Management Proceedings. 1-7. Retrieved November 9, 2007, from: http://web.ebscohost.com

Spencer, L. M., \& Spencer, S. M. (1993). Competence at work: Models for superior performance. New York: Wiley.

United States Air Force. Air University. (2007). Strategic Leadership Studies. Retrieved Dece mber 30, 2007, from: http://leadership.au.af.mil/sls-skil.htm

Warrenfeltz, R. B. (1995). An executive-level validation of the Borman and Brush taxonomy. Paper presented at the 10th Annual Conference of the Society for Industrial and Organizational Psychology. Orlando, FL

Zimmerman, B. J. (2000). Self-efficacy: An essential motive to learn. Contemporary Educational Psychology, 25(1), 82-91.

\section{Biographies}

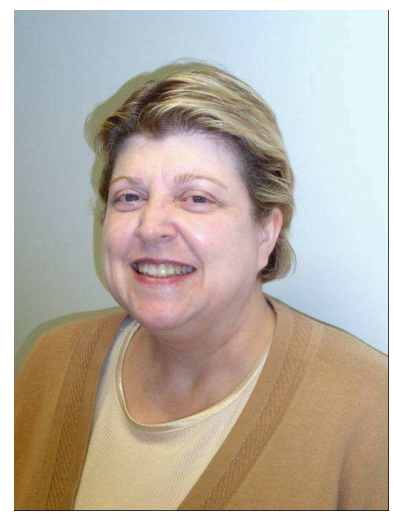

Nancy A. Inskeep, Esq. is a consultant who has led projects and implemented key business strategies for more than 25 years in financial services, telecommunications, and retail environments. She has served as project leader in the selection and implementation of human resources, investment, materials management, and customer services, as well as vendor relationship management and financial analys is. Nancy holds a JD, an M.Ed., and an MBA. She is PMP certified and has published on topics involving law, project management, and HRIS systems. She has been the principal consultant of Organization \& Guidance Consulting and recently co-founded $\underline{\mathrm{HI} \text { Results Consulting. }}$

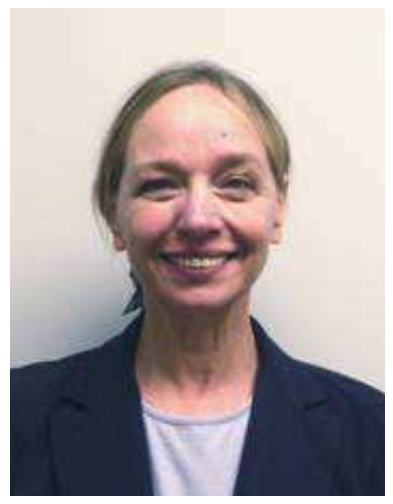

Bettie C. Hall, Ed.D., is a consultant with more than 25 years of experience assisting organizations design, implement, and support information technology systems. She has published and presented on topics ranging from how to choose technologies that address adult learning styles to creating reward systems that motivate people to do the ir best. She holds a doctorate in education with a specialization in knowledge technologies, and has helped launch HI Results Consulting with a goal of using educational research to improve business results. 